\title{
VISÕES DA EDUCAÇÃO DE JOVENS E ADULTOS NO BRASIL
}

\author{
Maria Clara Di Pierro \\ ORLANDO Joia \\ Vera Masagão Ribeiro*
}

\begin{abstract}
RESUMO: Este artigo discute a situação atual da Educação de Jovens e Adultos no Brasil. Iniciando a discussão por uma revisão histórica das políticas de educação de adultos nas grandes reformas educacionais deste século, conclui com uma análise das possibilidades de realizar uma educação em suplência que de forma renovada não caia na repetição dos erros do passado nem escolarize demais este nível de ensino.
\end{abstract}

Palavras-chave: Política Educacional; Política de Educação de Jovens e Adultos; Brasil.

A educação de jovens e adultos é um campo de práticas e reflexão que inevitavelmente transborda os limites da escolarização em sentido estrito. Primeiramente, porque abarca processos formativos diversos, onde podem ser incluídas iniciativas visando a qualificação profissional, o desenvolvimento comunitário, a formação política e um sem número de questóes culturais pautadas em outros espaços que não o escolar. Além disso, mesmo quando se focalizam os processos de escolarização de jovens e adultos, o cânone da escola regular, com seus tempos e espaços rigidamente delimitados, imediatamente se apresenta como problemático. Trata-se, de fato, de um campo pedagógico fronteiriço, que bem poderia ser aproveitado como terreno fértil para a inovação prática e teórica. Quando se adotam concepções mais restritivas sobre o fenômeno educativo, entretanto, o lugar da educação de jovens e adultos pode ser entendido como marginal ou secundário, sem maior interesse do ponto de vista da formulação política e da reflexão pedagógica. Quando, pelo contrário, a abordagem do fenômeno educativo é ampla e sistêmica, a educação de jovens e adultos é necessariamente considerada como parte integrante da história da educação em nosso país, como uma das arenas

\footnotetext{
* Assessores da Organização Ação Educativa - Assessoria, Pesquisa e Informação. E-mail: acaoeduca@acaoeducativa.org
} 
importantes onde vêm se empreendendo esforços para a democratização do acesso ao conhecimento.

O objetivo deste artigo é, a partir de uma concepção ampla e sistêmica da problemática educacional brasileira, procurar identificar como as práticas de educação de jovens e adultos, assim como a reflexão pedagógica em torno delas, foram traçando uma história particular, que encerra mais que a sucessão de iniciativas pontuais e provisórias, em torno das quais não se gera nenhum acúmulo. Elegendo como foco as políticas de escolarização básica de jovens e adultos, o artigo propõe inicialmente uma análise retrospectiva, remetendo-a em seguida a um balanço da conjuntura atual e ao esboço de perspectivas de futuro.

\section{Uma visão retrospectiva}

No Brasil, a educação de adultos se constitui como tema de política educacional sobretudo a partir dos anos 40. A menção à necessidade de oferecer educação aos adultos já aparecia em textos normativos anteriores, como na pouco duradoura Constituição de 1934, mas é na década seguinte que começaria a tomar corpo, em iniciativas concretas, a preocupação de oferecer os benefícios da escolarização a amplas camadas da população até então excluídas da escola. Essa tendência se expressou em várias ações e programas governamentais, nos anos 40 e 50 . Além de iniciativas nos níveis estadual e local, merecem ser citadas, em razão de sua amplitude nacional: a criação do Fundo Nacional de Ensino Primário em 1942, do Serviço de Educação de Adultos e da Campanha de Educação de Adultos, ambos em 1947, da Campanha de Educação Rural iniciada em 1952 e da Campanha Nacional de Erradicação do Analfabetismo em 1958.

Celso Beisiegel (1997) destaca o caráter exemplar da Campanha Nacional de Educação de Adultos iniciada em 1947 - capitaneada por Lourenço Filho - como política governamental que exprimia o entendimento da educação de adultos como peça fundamental na elevação dos níveis educacionais da população em seu conjunto. Além do necessário enfrentamento direto do problema do analfabetismo adulto, Lourenço Filho já então destacava os efeitos positivos da educação dos adultos sobre a educação das crianças, ambas componentes indissociáveis de um mesmo projeto de elevação cultural dos cidadãos. Beisiegel chama a atenção ainda para o papel indutor que a União então assumiu, provocando a iniciativa das unidades federadas por meio da regulamentação da distribuição de fundos públicos, contemplando percentuais destinados à 
estruturação de serviços de educação primária para os jovens e adultos. Essa orientação política viabilizou a criação e permanência do ensino supletivo integrado às estruturas dos sistemas estaduais de ensino. Em São Paulo, por exemplo, o Serviço de Educação de Adultos pôde funcionar regularmente até os anos 70, quando entraria em ação o Mobral.

A Campanha de 1947 deu também lugar à instauração no Brasil de um campo de reflexão pedagógica em torno do analfabetismo e suas conseqüências psicossociais; entretanto, ela não chegou a produzir nenhuma proposta metodológica específica para a alfabetização de adultos, nem um paradigma pedagógico próprio para essa modalidade de ensino. Isso só viria a ocorrer no início dos anos 60, quando o trabalho de Paulo Freire passou a direcionar diversas experiências de educação de adultos organizadas por distintos atores, com graus variados de ligação com o aparato governamental. Foi o caso dos programas do Movimento de Educação de Base (MEB), do Movimento de Cultura Popular do Recife, ambos iniciados em 1961, dos Centros Populares de Cultura da União Nacional dos Estudantes, entre outras iniciativas de caráter regional ou local. Embaladas pela efervescência política e cultural do período, essas experiências evoluíam no sentido da organização de grupos populares articulados a sindicatos e outros movimentos sociais. Professavam a necessidade de realizar uma educação de adultos crítica, voltada à transformação social e não apenas à adaptaçã̃o da população a processos de modernização conduzidos por forças exógenas. O paradigma pedagógico que então se gestava preconizava com centralidade o diálogo como princípio educativo e a assunção, por parte dos educandos adultos, de seu papel de sujeitos de aprendizagem, de produção de cultura e de transformação do mundo.

Em 1964, o Ministério da Educação organizou o último dos programas de corte nacional desse ciclo, o Programa Nacional de Alfabetização de Adultos, cujo planejamento incorporou largamente as orientações de Paulo Freire. Essa e outras experiências acabaram por desaparecer ou desestruturar-se sob a violenta repressão dos governos do ciclo militar iniciado naquele mesmo ano. $\mathrm{O}$ exílio não impediria, entretanto, que o educador Paulo Freire continuasse a desenvolver no exterior sua proposta de alfabetização de adultos conscientizadora, utilizando palavras geradoras que, antes de serem analisadas do ponto de vista gráfico e fonético, serviam para sugerir a reflexão sobre o contexto existencial dos jovens e adultos analfabetos, sobre as causas de seus problemas e as vias para sua superação. O fechamento político e institucional que caracterizou a conjuntura brasileira nos anos 70 também não impediu que sobrevivessem ou emergissem açôes educativas voltadas à alfabetização 
e pós-alfabetização inspiradas pelo paradigma freireano. Abrigadas freqüentemente em igrejas, associaçóes de moradores, organizações de base local e outros espaços comunitários, essas iniciativas experimentaram propostas de alfabetização e pós-alfabetização de adultos que se nutriram no paradigma da educação popular, impulsionando a busca de uma adequação de metodologias e conteúdos às características etárias e de classe dos educandos.

A partir de 1969, o governo federal organizou o Mobral (Movimento Brasileiro de Alfabetização), um programa de proporções nacionais, proclamadamente voltado a oferecer alfabetização a amplas parcelas dos adultos analfabetos nas mais variadas localidades do país. Diferentemente do que ocorrera na Campanha de 1947, o governo federal investiu um volume significativo de recursos na montagem de uma organização de âmbito nacional e autônoma em relação às secretarias estaduais e ao próprio Ministério da Educação. O Mobral instalou comissóes municipais por todo o país, responsabilizando-as pela execução das atividades, enquanto controlava rígida e centralizadamente a orientação, supervisão pedagógica e produção de materiais didáticos. Sendo concebido como ação que se extinguiria depois de resolvido o problema do analfabetismo, o Mobral tinha baixa articulação com o sistema de ensino básico. Em virtude de sua presença maciça no país e sua capilaridade, contribuiu para legitimar a nova ordem política implantada em 1964. Além da legitimação interna, esta iniciativa governamental também visava responder a orientações emanadas de agências internacionais ligadas à Organização das Nações Unidas, em especial a Unesco, que desde o final da Segunda Guerra vinham propugnado o valor do combate ao analfabetismo e da universalização de uma educação elementar comum como estratégia de desenvolvimento socioeconômico e manutenção da paz.

Ao longo dos anos 70, o Mobral diversificou sua atuação visando a sua sobrevivência e, mais para o final do período, a responder às críticas em relação à falácia dos números que apresentava como resultado ou à insuficiência do domínio rudimentar da escrita que era capaz de promover. Um dos desdobramentos mais importantes nessa linha de diversificação foi a criação de um programa que correspondia a uma condensação do antigo curso primário, assentando as bases para a reorganização de iniciativas mais sistêmicas que viabilizassem a continuidade da alfabetização em programas de educação básica para jovens e adultos.

Desacreditado nos meios políticos e educacionais, o Mobral foi extinto em 1985, quando o processo de abertura política já estava relativamente avançado. $\mathrm{O}$ montante de recursos de que dispunha já havia 
diminuído muito e o que restava de sua estrutura foi assimilado pela então criada Fundação Educar, que passou a apoiar técnica e financeiramente iniciativas de governos estaduais e municipais e entidades civis, abrindo mão do controle político pedagógico que caracterizara até então a ação do Mobral. Nesse período, muitos programas governamentais acolheram educadores ligados a experiências de educação popular, possibilitando a confluência do ideário da educação popular - até então desenvolvido prioritariamente em experiências de educação não formal - com a promoção da escolarização de jovens e adultos por meio de programas mais extensivos de educação básica.

Para tanto, um novo enquadramento legal já estava disponível: a Lei Federal 5692, que em 1971 consagrara a extensão da educação básica obrigatória de 4 para 8 anos - constituindo o então denominado ensino de primeiro grau - e, concomitantemente, dispôs as regras básicas para o provimento de educação supletiva corresponde a esse grau de ensino aos jovens e adultos. Pela primeira vez, a educação voltada a esse segmento mereceu um capítulo específico na legislação educacional, que distinguiu as várias funções: a suplência - relativa à reposição de escolaridade -, o suprimento - relativa ao aperfeiçoamento ou atualização -, a aprendizagem e a qualificação - referentes à formação para o trabalho e profissionalização.

Um dos componentes mais significativos do atendimento educativo preconizado pela Lei 5692/71 àqueles que não haviam realizado ou completado na idade própria a escolaridade obrigatória foi a flexibilidade. Prevista na letra da lei, ela se concretizou na possibilidade de organização do ensino em várias modalidades: cursos supletivos, centros de estudo e ensino a distância, entre outras. Nos cursos, freqüentemente vigoram a seriação, a presença obrigatória e a avaliação no processo; sua característica diferencial é a aceleração, pois o tempo estipulado para a conclusão de um grau de ensino é, no mínimo, a metade do previsto para o sistema regular. Os centros de estudo oferecem aos alunos adultos material didático em módulos e sessões de estudos para as quais a freqüência é livre. A avaliação é feita periodicamente, por disciplina e módulo. As iniciativas de educação a distância dominantes são as que se realizam por televisão, em regime de livre recepção ou (muito raramente) recepção organizada, em telepostos que combinam reprodução de programas em vídeo, uso de materiais didáticos impressos e acompanhamento de monitor. Além dessas modalidades, a Lei 5692 manteve os exames supletivos, como mecanismo de certificação, atualizando exames de madureza já existentes há longa data. Os candidatos, aqueles preparados 
por meio do ensino a distância ou cursos livres ou ainda aqueles sem preparação específica que desejam atestar seus conhecimentos, se submetem periodicamente - duas vezes ao ano como regra geral - a exames finais organizados pelos estados, por disciplina e sem nenhuma exigência de matrícula ou freqüência à sala de aula.

A extensão da escolaridade obrigatória para oito anos, proposta da Lei 5692, representava um enorme desafio, já que colocava em condição de déficit educativo um enorme contingente da população adulta, da qual o ensino supletivo estaria a serviço. Entretanto, essa mesma legislação limitou a obrigatoriedade da oferta pública do ensino de primeiro grau apenas às crianças e adolescentes na faixa de 7 a 14 anos. $O$ direito, mais amplo, à educação básica, só seria estendido aos jovens e adultos na Constituição Federal de 1988, como resultado do envolvimento no processo constituinte de diversos setores progressistas que se mobilizaram em prol da ampliação dos direitos sociais e das responsabilidades do Estado no atendimento às necessidades dos grupos sociais mais pobres.

Estudo realizado por Siqueira, Freitas \& Haddad (1988) constata que à época da promulgação desse texto constitucional, o ensino supletivo já havia se implantado efetivamente em todo o território nacional, embora de modo heterogêneo. Os autores observam, entretanto, a insuficiência da cobertura face à demanda existente, além de dificuldades de ordem política, administrativa, financeira e pedagógica que limitavam a extensão e a qualidade do ensino oferecido. Esse segmento de ensino foi atendido predominantemente por meio de modalidades não presenciais, nas quais a baixa interação professor-aluno e a flexibilidade de organização se associam a baixos custos de funcionamento.

Os programas correspondentes às séries iniciais - denominados Suplência I, deram continuidade a experiências de alfabetização que, em grande medida graças à influência das propostas de Paulo Freire, lograram delimitar alguma identidade pedagógica. Esses programas também puderam compor um leque de ofertas mais diversificado, tanto no que se refere aos promotores e locais de funcionamento dos cursos - escolas, igrejas, sindicados e centros comunitários - quanto à duração e periodização das etapas. Tal liberdade se deveu, certamente, ao fato de que tais programas já não encerravam a terminalidade de um nível de ensino com sua correspondente certificação.

O contrário ocorreu com os cursos de Suplência II, correspondentes às séries finais do ensino fundamental, que tiveram de se submeter a regulamentações mais rígidas por parte dos conselhos de educação. É fato que se pode constatar uma grande diversidade de programas ofere- 
cidos nos estados, com predomínio das modalidades não presenciais. Entretanto, quando se analisam os currículos desses programas, o que se constata é uma grande homogeneidade na reprodução dos conteúdos do ensino regular, sua organização nas disciplinas e seqüenciação (Joia et al., 1999). São poucas as experiências que inovaram nesse sentido, experimentando novos eixos curriculares e novas formas de organizar os tempos e espaços de aprendizagem, sem partir para a individualização implicada nas modalidades não presenciais.

Um elemento que vem complicar a construção de uma identidade pedagógica do ensino supletivo e de sua adequação às características específicas da população a que se destina é o processo notado em todas as regióes do país, assim como em outros países da América Latina, de juvenilização da clientela. O paradigma da educação popular de inspiração freireana, que serviu como referência para os educadores interessados em qualificar o ensino supletivo e aproximá-lo das necessidades educativas de seu alunado, havia dominantemente tomado em consideração os educandos adultos desescolarizados, trabalhadores que, mesmo morando nas grandes cidades, mantinham grandes vínculos com uma cultura rural. O que ocorre, entretanto, é que a clientela dos cursos supletivos tornavase crescentemente mais jovem e urbana, em função da dinâmica escolar brasileira e das pressões oriundas do mundo do trabalho. Nesse sentido, mais do que uma "nova escola", voltada a um novo público, antes não atendido pela escola básica insuficiente, a educação supletiva converteuse também em mecanismo de "aceleração de estudos" para adolescentes e jovens com baixo desempenho na escola regular.

As conhecidas deficiências do sistema escolar regular público são, sem dúvida, responsáveis por parte da demanda do público mais jovem sobre os programas de ensino supletivo. Os dados sobre a defasagem entre a idade e a série, no ensino regular, pela sua magnitude, apontam nessa direção: em 1996, a Contagem da População (IBGE, 1997) constatava a existência de 5,3 milhões de pessoas de 15 a 19 anos freqüentando a escola em situação de defasagem de ano ou mais. $\mathrm{O}$ índice de defasagem aumenta progressivamente com a idade, chegando próximo de $90 \%$ entre jovens de 18 anos. A entrada precoce dos adolescentes das camadas mais pobres no mercado de trabalho formal ou informal provocou a sua transferência para os programas de educação originalmente destinados à população adulta. Levantamentos realizados em vários estados comprovam essa tendência. Em 1992, constatava-se que dos alunos do programa municipal de ensino supletivo, 26\% tinham até dezoito anos e 36\% tinham entre dezenove e 26 anos (São Paulo, 1992). No Recife, em programa seme- 
lhante, 48\% tinham entre 13 e 18 anos de idade e 26\% entre 18 e 24 (Recife, 1995). No estado do Mato Grosso, constatou-se num estudo amostral que, em 1997, 47,5\% dos alunos do supletivo haviam abandonado o ensino regular no ano da pesquisa ou nos três anos anteriores, a maior parte motivada pelo trabalho (Mato Grosso, 1998).

A entrada precoce no mercado de trabalho e o aumento das exigências de instrução e domínio de habilidades no mundo do trabalho constituem os fatores principais a direcionar os adolescentes e jovens para os cursos de suplência, que aí chegam com mais expectativas que os adultos mais velhos de prolongar a escolaridade pelo menos até o ensino médio para inserir-se ou ganhar mobilidade no mercado de trabalho. Nesse contexto, a suplência passou a constituir-se em oportunidade educativa para um largo segmento da população, com três trajetórias escolares básicas: para os que iniciam a escolaridade já na condição de adultos trabalhadores; para adolescentes e adultos jovens que ingressaram na escola regular e a abandonaram há algum tempo, freqüentemente motivados pelo ingresso no trabalho ou em razão de movimentos migratórios e, finalmente, para adolescentes que ingressaram e cursaram recentemente a escola regular, mas acumularam aí grandes defasagens entre a idade e a série cursada.

Esse quadro de demanda potencial e as garantias constitucionais sobre direitos educativos com que se chegou ao final dos anos 80 fariam supor que a década seguinte seria de ampliação significativa do atendimento e multiplicação de iniciativas visando fazer frente aos enormes desafios pedagógicos colocados para a educação de jovens e adultos no contexto de consolidação da democracia, concomitantemente ao crescente agravamento da situação econômica do país. Não seria isso, entretanto, exatamente ao que se assistiria nessa década, o que nos convida a refletir sobre o inevitável sentido político das opçôes tomadas nesse campo educativo, cujo mandato principal é o de reverter a enorme dívida social gerada por um modelo de desenvolvimento que não promove a justiça social.

\section{Uma visão dos anos 90}

É conveniente iniciar a análise da situação da educação de jovens e adultos na última década do milênio com um quadro mais preciso da magnitude da demanda potencial por essa modalidade educativa. A contagem da população realizada pelo IBGE em 1996 verificou que entre os brasileiros com 15 anos ou mais, 15,3 milhões (14,2\%) não completaram sequer um ano de escolaridade, 19,4 milhões $(18,2 \%)$ 
têm apenas de um a três anos de instrução e outros 36 milhões $(33,8 \%)$ completaram de quatro a sete anos. Totalizando esses dados, podemos constatar que são 70,7 milhões (66,2\% dos brasileiros com 15 anos ou mais) os que não completaram o ensino fundamental e que, segundo a Constituição, teriam direito ao ensino fundamental gratuito adequado à sua condição de jovens e adultos trabalhadores. Se quisermos ainda considerar a intenção expressa no texto constitucional de universalização do ensino médio, teríamos que acrescentar a esse contingente os 23,3 milhões de brasileiros com 20 anos ou mais que puderam concluir o ensino fundamental, mas não o médio. Segundo levantamentos do Ministério da Educação e do Desporto (MEC), entre 1995 e 1998, o número de matrículas iniciais no ensino fundamental de jovens e adultos ficou em torno dos 2 milhões. No que se refere à alfabetização, o índice de cobertura não chega a $1 \%$; quanto ao acesso ao ensino fundamental, temos $8,41 \%$ dos jovens e adultos cursando o sistema regular com alguma defasagem entre a idade e a série e apenas $4 \%$ freqüentando cursos para jovens e adultos; como pode ser visualizado no quadro abaixo:

População com 15 anos ou mais por anos de estudo e freqüência ao ensino fundamental (1996)

\begin{tabular}{|c|c|c|c|c|c|c|c|}
\hline \multicolumn{6}{|c|}{ Anos de estudo da população com 15 anos ou mais } \\
\hline \multirow{3}{*}{ Sem instruçáo e menos de 1 ano } & \multicolumn{5}{|c|}{1 a 7 anos } \\
\hline \multirow{2}{*}{ TOTAL } & \multicolumn{2}{|c|}{ Frequêênta escola } & \multirow{2}{*}{ TOTAL } & \multicolumn{4}{|c|}{ Freqüenta escola } \\
\cline { 2 - 5 } & $\begin{array}{c}\text { Alfabetizaçáo } \\
\text { de Adultos }\end{array}$ & $\%$ & & $\begin{array}{c}\text { Ensino } \\
\text { fundamental } \\
\text { regular }\end{array}$ & $\%$ & $\begin{array}{c}\text { Ensino } \\
\text { fundamental } \\
\text { de adultos }\end{array}$ & $\%$ \\
\hline 15.150 .760 & 97.815 & 0,65 & 55.324 .958 & 4.652 .773 & 8,41 & 2.210 .325 & 4,00 \\
\hline
\end{tabular}

Fontes: IBGE. Contagem da População: 1996; Inep. Sinopse estatística da educação básica. Censo escolar 1997.

Dirigindo agora o foco de análise para as políticas que marcaram o período, vale mencionar que, em 1990, foi extinta a Fundação Educar, sucedânea do Mobral, logo após a posse do governo Fernando Collor de Mello - primeiro presidente eleito diretamente após o regime militar. O MEC desencadeou o Programa Nacional de Alfabetização e Cidadania (PNAC), com o objetivo proclamado de mobilizar a sociedade em prol da alfabetização de crianças, jovens e adultos por meio de comissões envolvendo órgãos governamentais e não-governamentais. Entretanto, as comissões não puderam exercer nenhum controle sobre a destinação de recursos e o programa foi encerrado depois de um ano. Personalidades influentes sobre as políticas educacionais, como o ex-Ministro José 
Goldenberg e o consultor Cláudio Moura Castro, bem como os já falecidos Senador Darcy Ribeiro e Sérgio Costa Ribeiro, pesquisador do IPEA, declararam publicamente opor-se a que os governos invistam na educação de adultos, argumentando que os adultos analfabetos já estariam adaptados à sua condição e que o atraso educativo do país poderia ser saldado com a focalização dos recursos no ensino primário das crianças (Beisiegel, 1997).

A falta de incentivo político e financeiro por parte do governo federal levou os programas estaduais - responsáveis pela maior parte do atendimento à educação de jovens e adultos - a uma situação de estagnação ou declínio. Muitos municípios herdeiros de programas anteriormente realizados em convênio com a Fundação Educar foram obrigados a assumi-los com recursos próprios, muitas vezes sem o necessário preparo gerencial e técnico. Haddad et al. (1993) verificaram, por meio de amplo estudo, a tendência de municipalização do atendimento aos jovens e adultos, o que, segundo o autor, estaria resultando mais da omissão das esferas federal e estadual do que de uma política coordenada de descentralização.

Esse retrocesso no plano das políticas também exprimiu-se no quadro legal, por meio de duas medidas restritivas tomadas durante o governo de Fernando Henrique Cardoso. Em 1996, uma emenda à Constituição suprimiu a obrigatoriedade do ensino fundamental aos jovens e adultos, mantendo apenas a garantia de sua oferta gratuita. Essa formulação desobriga o Estado de uma ação convocatória e mobilizadora no campo da educação de adultos e, segundo Fávero et al. (1999), também o dispensa de aplicar verbas reservadas ao ensino fundamental no atendimento dos jovens e adultos. De fato, ao criar o Fundo de Manutenção e Desenvolvimento do Ensino Fundamental e Valorização do Magistério (Fundef), o governo excluiu as matrículas no ensino supletivo do cômputo do alunado do ensino fundamental, que é a base de cálculo para os repasses de recursos para estados e municípios, desestimulando a ampliação de vagas. A nova Lei de Diretrizes e Bases (LDB), promulgada em 1996, por sua vez, diluiu as funções do ensino supletivo nos objetivos e formas de atendimento do ensino regular para crianças, adolescentes e jovens. Enquanto isso, manteve a ênfase nos exames e, ao rebaixar a idade mínima para o acesso a essa forma de certificação de 18 para 15 anos no ensino fundamental e de 21 para 18 no ensino médio, sinalizou para as instâncias normativas estaduais a identificação cada vez maior entre o ensino supletivo e os mecanismos de aceleração do ensino regular, medida cada vez mais aplicada nos estados e municípios, visando à correção do 
fluxo no sistema. Também para driblar a restrição do Fundef quanto à consideração dos alunos dos cursos supletivos entre os atendidos no ensino fundamental, muitos municípios estão convertendo esses cursos em programas regulares acelerados, o que também contribui para aproximar a educação de jovens e adultos do ensino regular acelerado, além de confundir as estatísticas educacionais.

Esse processo de deslegitimação da educação de jovens e adultos no conjunto das políticas educacionais não foi um fenômeno apenas nacional; resultou, de fato, de uma conjuntura internacional que afetou outros países em desenvolvimento. Nessa conjuntura, agências internacionais de fomento e financiamento da educação tiveram papel destacado, influenciando os governos nacionais na condução de reformas educativas, que tiveram características surpreendentemente homogêneas, considerando a diversidade da realidade dos países em desenvolvimento ao redor do globo.

No contexto internacional, o início dos anos 90 foi marcado por um evento inédito que muito prometia em relação ao futuro da educação de jovens e adultos. Em 1990, declarado pela Organização das Nações Unidas como Ano Internacional da Alfabetização, realizou-se em Jonthien, na Tailândia, uma Conferência Mundial que reuniu entre seus patrocinadores, pela primeira vez, a Unesco (Organização das Nações Unidas para a Educação, Ciência e Cultura), o PNUD (Programa das Nações Unidas para o Desenvolvimento), o Unicef (Fundo das Nações Unidas para a Infância) e o Banco Mundial. Aí foi aprovada a Declaração Mundial sobre Educação para Todos, que propunha uma abordagem global do problema educacional no mundo, uma importante ampliação do conceito de educação básica e ações coordenadas em vários níveis. Muitas das orientaçôes dessa conferência dinamizaram reformas educativas que haviam se iniciado na década anterior em países em desenvolvimento, evidenciando que a educação ganhava destaque entre as demais políticas sociais. A Declaração de Jonthien deu destaque à educação de jovens e adultos, incluindo metas relativas à redução de taxas de analfabetismo, além da expansão dos serviços de educação básica e capacitação aos jovens e adultos, com avaliação sobre seus impactos sociais.

Fazendo balanço da década da "Educação para Todos", Rosa Maria Torres (1999) observa que as políticas implementadas expressaram um estreitamento do conceito de educação básica proposto no documento. Resultado do acordo entre agências com distintas orientações, o documento permitia diversas interpretações, sendo que a visão que se hegemonizou foi a que identificava a educação básica com a educação primária de 
crianças, foco privilegiado, quase exclusivo, da maioria das reformas educativas que tiveram lugar nos países em desenvolvimento. A autora argumenta que esse estreitamento já podia ser antevisto na lista de indicadores selecionados para avaliar a década: os referidos à educação de jovens e adultos continuaram centrados na alfabetização inicial e não na educação básica em seu sentido amplo. Também os estudos e estimativas de custos que se seguiram à Conferência só consideraram as metas relacionadas à universalização da educação primária à população infantil. Os organismos bilaterais e multilaterais passaram a desestimular abertamente o investimento em educação de adultos. Lamentando essa situação, Rosa Maria Torres pontua:

Tudo isso é preocupante não só pelo abandono educativo de jovens e adultos enquanto tais, mas também pela visão estreita que tal descuido revela em relação à própria meta (considerada prioritária) da universalização da educação primária infantil. Deixar de lado a educação de adultos é ignorar mais uma vez o ponto de vista da demanda educativa, a importância da família como suporte fundamental para o bem estar e a aprendizagem infantil, e, em última instância, como fator relevante nas condições de aprendizagem no meio escolar. Educar os adultos-pais e mães de família e os adultos-comunidade é indispensável para o alcance da própria Educação Básica para Todas as Crianças, e educar os adultosprofessores é condição sine qua nom para expandir e melhorar as condições de ensino. (Torres, 1999, p. 20)

Essa avaliação do cenário educacional mundial, à luz nos compromissos firmados em Jonthien, corresponde bastante ao que ocorreu no Brasil durante essa década. É o que constatam Haddad \& Di Pierro (1999), analisando o que aqui ocorreu com os índices de analfabetismo, geração de novos contingentes de analfabetos funcionais devido à ação deficiente dos sistemas regulares de ensino, restrição de direitos legais, insuficiência da cobertura dos serviços face à demanda, limites do financiamento e, em especial, omissão do governo federal na indução e coordenação das iniciativas das outras esferas de governo. Encerramos assim a última década do século, tendo de prorrogar para o próximo milênio uma investida mais decidida no sentido de superar a exclusão educativa e cultural de amplos setores da população, coordenando ações sistêmicas no campo da educação de crianças, jovens e adultos, na escola e fora dela.

\section{Uma visão prospectiva}

A demanda pelo ensino fundamental de jovens e adultos é extensa e complexa, comportando em seu interior uma grande diversidade 
de necessidades formativas. Primeiramente, devemos considerar a necessidade de consolidar a alfabetização funcional dos indivíduos, pois estudos atuais indicam que é preciso uma escolaridade mais prolongada para se formar usuários da linguagem escrita capazes de fazer dela múltiplos usos, com o objetivo de expressar a própria subjetividade, buscar informação, planejar e controlar processos e aprender novos corpos de conhecimento (Ribeiro, 1999). É forçoso considerar os requisitos formativos cada vez mais complexos para o exercício de uma cidadania plena, as exigências crescentes por qualificações de um mercado de trabalho excludente e seletivo e as demandas culturais peculiares a cada subgrupo etário, de gênero, étnico-racial, socioeconômico, religioso ou ocupacional. A pergunta que se coloca, então, é como contemplar com eqüidade um direito básico da cidadania, retendo sob um parâmetro comum de qualidade necessidades formativas táo diversas? A literatura e a experiência nacional e internacional indicam alguns caminhos para a solução desse impasse.

Um passo prévio implica superar a concepção de que a idade adequada para aprender é a infância e a adolescência e que a função prioritária ou exclusiva da educação de pessoas jovens e adultas é a reposição de escolaridade perdida na "idade adequada". Reconhecendo, de um lado, que jovens e adultos são cognitivamente capazes de aprender ao longo de toda a vida e que as mudanças econômicas, tecnológicas e socioculturais em curso neste final de milênio impóem a aquisiçãao e atualização constante de conhecimentos pelos indivíduos de todas as idades, propugna-se conceber todos os sistemas formativos nos marcos da educação continuada. Nestes marcos, os objetivos da formação de pessoas jovens e adultas não se restringem à compensação da educação básica não adquirida no passado, mas visam a responder às múltiplas necessidades formativas que os indivíduos têm no presente e terão no futuro. Sendo tais necessidades múltiplas, diversas e cambiantes, as políticas de formação de pessoas adultas deverão ser necessariamente abrangentes, diversificadas e altamente flexíveis.

O desenvolvimento de políticas de formação de pessoas jovens e adultas consoantes a esse novo paradigma de educação continuada é tema polêmico, mas uma revisão da literatura permite que identifiquemos algumas indicaçóes mais ou menos consensuais. A primeira delas relaciona-se ao reconhecimento do direito dos indivíduos traçarem com autonomia suas próprias biografias formativas. A segunda recomenda modificar o estilo de planejamento das agências formadoras, levando-as a realizar um "giro" da oferta para a demanda, ou seja, deixar de conceber a oferta educativa a partir de padrôes únicos (quase sempre referidos aos 
parâmetros da educação escolar de crianças e adolescentes), passando a concebê-la a partir da diversidade de demandas concretas dos diferentes segmentos sociais. A terceira implica reconhecer que não apenas a escola, mas muitas outras instituições e espaços sociais têm potencial formativo - o trabalho e as empresas, os meios de comunicação, as organizações comunitárias, os equipamentos públicos de saúde, cultura, esportes e lazer etc. -, aproveitando ao máximo esse potencial e reconhecendo a legitimidade do conhecimento adquirido por meios extra-escolares.

Superar a concepção compensatória de educação de pessoas adultas não implica, porém, negar que há desigualdades educativas a serem enfrentadas. A tendência histórica à ampliação e alongamento da educação básica vem produzindo aquilo que os sociólogos da educação denominam "efeito desnivelador": cada vez que se amplia a escolaridade mínima obrigatória, um novo contingente de jovens e adultos fica com uma escolaridade inferior àquela a que todo cidadão tem direito (Flecha Garcia, 1996). Assegurar essa escolaridade mínima comum é responsabilidade da qual o poder público não pode esquivar-se, ainda que possa contar com a colaboração da sociedade civil organizada para efetivá-la.

Isso não significa que a educação básica de jovens e adultos deva reproduzir as formas de organização, currículos, métodos e materiais da educação básica infanto-juvenil. Muito ao contrário, a experiência internacional recomenda flexibilizar currículos, meios e formas de atendimento, integrando as dimensões de educação geral e profissional, reconhecendo processos de aprendizagem informais e formais, combinando meios de ensino presenciais e a distância, de modo a que os indivíduos possam obter novas aprendizagens e a certificação correspondente mediante diferentes trajetórias formativas. Isso implica:

- Descentralizar o sistema de ensino e conceder autonomia aos centros educativos para que formulem projetos pedagógicos pertinentes às necessidades educativas das comunidades em que estão inseridos, convertendo-se estes no locus privilegiado de desenvolvimento curricular;

- Flexibilizar a organização curricular e assegurar certificação equivalente para percursos formativos diversos, facultando aos indivíduos que autodeterminem suas biografias educativas, optando pela trajetória mais adequada às suas necessidades e características; - Prover múltiplas ofertas de meios de ensino-aprendizagem, presenciais ou a distância, escolares e extra-escolares, facultando a circulação e o aproveitamento de estudos nas diferentes modalidades e meios; 
- Aperfeiçoar os mecanismos de avaliação, facultar a creditação de aprendizagens adquiridas na experiência pessoal e/ou profissional ou por meio de ensinos não-formais, diversificando e flexibilizando os meios de acesso a níveis de escolaridade mais elevados.

Outro problema nodal da educação de jovens e adultos diz respeito à articulação entre a formação geral e profissional. Embora as motivações para que jovens e adultos participem de programas formativos sejam múltiplas e não necessariamente instrumentais, a melhoria profissional e ocupacional é o motivo declarado da maioria dos estudantes. Ainda que o trabalho venha perdendo a centralidade que teve no passado recente na construção das identidades dos sujeitos e grupos sociais, ele continua a ser um fator importante nessa construção, especialmente nas camadas sociais em que ele é a fonte exclusiva para prover os meios de subsistência. A contração e o acirramento da competição no mercado de trabalho no período recente só veio tornar mais explícitas e urgentes as necessidades de qualificação profissional das pessoas adultas.

A formação dos cidadãos para participar do mundo do trabalho coloca-se de maneira distinta quando o público é constituído por crianças e adolescentes ou por jovens e adultos. Se os primeiros deveriam ser poupados do trabalho precoce e preparados para uma inserção futura no mundo do trabalho, os últimos já estão, de uma ou outra forma, nele inseridos. O ideário mais aceito atualmente sobre a formação para o trabalho de crianças e adolescente valoriza a base comum de educação geral e, no seu interior, a formação científica e tecnológica, remetendo a qualificação profissional e a capacitação técnica para o posto de trabalho para uma etapa posterior à educação básica (no caso brasileiro, no ensino pós-médio ou superior). Quando o público da educação básica é constituído por jovens e adultos já inseridos no mercado de trabalho, entretanto, essa segmentação entre formação geral e capacitação profissional dificilmente se sustenta. É evidente que a base geral comum da formação e dos saberes científico-tecnológicos é igualmente importante, pois caso contrário iria reproduzir-se o velho dualismo de sistemas formativos propedêuticos e profissionalizantes. Mas não há razões objetivas para não potencializar simultânea e mutuamente processos de formação geral e capacitação profissional.

Os currículos do ensino fundamental, entretanto, não encaram esse problema de frente. De um lado, a precariedade material e pedagógica em que os programas se desenvolvem e as escolas funcionam sequer assegura a base formativa científico-tecnológica comum; de outro, a insis- 
tente referência ao ensino regular infanto-juvenil, a rigidez da seriação e das grades curriculares obrigatórias limitam a criatividade e dificultam a combinação de processos de formação geral e profissional. Como fazê-lo, sem cair nas armadilhas da dualização do sistema educativo ou da mera capacitação técnica para postos de trabalho de rápida obsolescência? Ao longo das últimas décadas, algumas experiências desenvolveram propostas interessantes voltadas ao equacionamento dessa questão, mas trata-se de um campo que ainda precisa de muita experimentação.

Ao lado da formação para o trabalho, é preciso também incorporar no currículo do ensino fundamental de jovens e adultos a formação política para a cidadania moderna. Uma das características do pensamento pedagógico referido à educação de jovens e adultos dos últimos 40 anos tem sido a explicitação do caráter político dos processos educativos e, conseqüentemente, o claro enunciado nos projetos pedagógicos destinados a estes grupos etários de objetivos de formação para a cidadania política. A pedagogia libertadora de Paulo Freire foi uma das fontes dessa explicitação do caráter político da educação, conformando a matriz do paradigma da educação popular que informou toda uma diversidade de práticas educativas formais ou não-formais. $\mathrm{O}$ enraizamento do paradigma da educação popular nas experiências de movimentos sociais e políticos que se constituíram como núcleos de resistência a regimes ditatoriais, que vigoraram durante os anos 70 em muitos países da América Latina, conferiu-lhe substância e densidade, mas acabou por confiná-lo ao campo ideológico das esquerdas, o que gerou resistências e questionamentos em relação à sua vigência na conjuntura de redemocratização dos regimes políticos do continente. Ao longo dos anos 80 e 90, as mudanças políticas, econômicas, sociais e culturais operadas dos cenários mundial e latino-americano desencadearam um processo, ainda inconcluso, de refundamentação teórico-prática do paradigma da educação popular.

De outro lado, a consciência de que as sociedades latino-americanas experimentam processos de construção democrática ainda não consolidados, coetâneos a uma crise econômica que aprofunda a exclusão, desgasta o tecido social, não favorece a integração e se faz acompanhar pelo crescimento da violência e por outros comportamentos disruptivos, fez com que emergisse outra vez no debate pedagógico a relevância da educação em valores e atitudes para a construção da autonomia moral dos indivíduos e, conseqüentemente, se revalorizasse a escola como agência de formação para a cidadania democrática. Essa tendência se expressa em documentos como os Parâmetros Curriculares Nacionais para o ensino fundamental, emanados recentemente pelo MEC, os quais, dada a visi- 
bilidade, capacidade de ação institucional desse órgão, tendem a influenciar o campo educativo. Tal documento, invocando o objetivo de construção da cidadania, elege a ética como tema transversal e orienta a educação escolar pelos princípios de respeito à dignidade da pessoa humana, a igualdade de direitos, a participação e co-responsabilidade pela vida social.

Assim, por impulsos diversos, a educação de jovens e adultos é convidada a reavaliar sua identidade e tradição, reelaborando os objetivos e conteúdos de formação política para a cidadania democrática que seus currículos sempre souberam explicitar. Cidadania é um conceito histórico, que comporta interpretaçôes mutáveis e diversas. Os debates atuais sobre os objetivos da educação para a cidadania privilegiam a formação de sujeitos livres, autônomos, críticos, abertos à mudança, capazes de intervir em processos de produção cultural que tenham alcance político. Os conteúdos propostos para a formação são afetados por reconstruções dos ideais da modernidade elaborados por diferentes correntes do pensamento social contemporâneo, que valorizaram sobretudo a horizontalidade do vínculo pedagógico, a comunicação intersubjetiva e o reconhecimento multicultural, a preservação de uma cena pública que permita a expressão de uma pluralidade de teses e discursos estratégicos provisórios, a resolução pacífica de conflitos e a elaboração democrática de consensos perante os dilemas éticos que afetam a sociedade contemporânea. É nesta sugestiva direção de formação política para a cidadania democrática que parece fecundo caminhar na reelaboração de currículos de educação de pessoas jovens e adultas.

Cabe considerar ainda que os currículos da educação escolar básica tradicionalmente selecionaram como conteúdos relevantes certos recortes do acervo de conhecimentos acadêmicos sistematizados e ordenados pelas disciplinas científicas ao longo da história e socialmente valorizados. A esse conjunto de conteúdos de ensino o jargão pedagógico nacional convencionou denominar "conhecimentos historicamente acumulados". A escolarização de jovens e adultos informada pelo paradigma da educação popular dialogou criticamente com essa tradição, porque se referiu, sobretudo, ao universo cultural dos educandos e questionou a valorização diferencial do conhecimento científico frente aos saberes construídos nas práticas de trabalho e convivência no meio popular. Suas referências curriculares foram fortemente influenciadas pela proposta freireana de eleição de temas geradores pertinentes à experiência sociocultural dos alunos, que induziam também a uma abordagem interdisciplinar do currículo. Essa concepção foi objeto de críticas que lhe atribuíam caráter 
populista ou redutor, especialmente quando o universo sociocultural dos educandos foi interpretado pelos educadores nos limites estritos da experiência cotidiana ou das suas demandas materiais ou políticas imediatas.

No período mais recente, diversas vertentes de pensamento pedagógico começaram a postular que as necessidades formativas das novas gerações exigem incorporar àquela base curricular tradicional temas emergentes da cultura contemporânea. É o caso, por exemplo, dos já citados Parâmetros Curriculares Nacionais propostos pelo MEC, que preconizam a estratégia de organização do trabalho didático denominada "transversalidade", incorporando certos conteúdos temáticos que perpassam as disciplinas e áreas de conhecimento. Partindo de quaisquer dessas tradições ou metodologias, há consenso de que os currículos da educação de jovens e adultos necessitam incorporar certos desafios éticos, políticos ou práticos da vida social contemporânea, relacionados ao exercício da moderna cidadania. Quatro temas relacionados às mudanças societárias operadas nesta transição de milênio parecem-nos muito relevantes para o currículo do ensino fundamental para jovens e adultos: meios de informação e comunicação; diversidade étnico-racial e multiculturalismo; meio ambiente e qualidade de vida; relações sociais de gênero e direitos da mulher.

Os aspectos arrolados acima indicam desafios a serem enfrentados num processo de qualificação da oferta dos serviços de educação de adultos. Entretanto, a história da educação de jovens e adultos no Brasil demonstra em que medida as iniciativas nesse campo exprimem orientações políticas e culturais amplas, especialmente no que se refere à maior ou menor incorporação de medidas que visem a eqüidade nos projetos de desenvolvimento social. É preciso, portanto, considerar também a necessidade de qualificar a demanda por esses serviços, por meio de ações culturais e políticas voltadas ao amplo reconhecimento do valor da educação continuada e do ensino fundamental de jovens e adultos como estratégias de promoção de eqüidade educativa e social.

Nesse sentido, os governos precisam assumir mais claramente uma atitude convocatória, chamando toda a sociedade a engajar-se em iniciativas voltadas a elevação do nível educativo da população. $\mathrm{O}$ teor desse chamado deveria contemplar, especialmente, a motivação para que todos continuem aprendendo ao longo da vida, de que a necessidade, a vontade e a possibilidade de aprender são inerentes a todos os seres humanos, do nascimento à velhice. A aprendizagem precisa ser assim compreendida em sentido amplo, como parte essencial da vida, e o desinteresse 
por aprender como eloqüente prenúncio da morte. Em tal contexto cultural, a educação de adultos poderia deixar de ser associada ao atraso e à pobreza e passar a ser tomada como indicador do mais alto grau de desenvolvimento econômico e social.

\section{VISIONS OF YOUTH AND ADULT EDUCATION IN BRAZIL}

ABSTRACT: This paper discusses the current situation of Youth and Adult Education in Brazil. The discussion begins by reviewing the adult educational policies within the huge educational reforms that marked last century and concludes analyzing the possibilities of achieving a high school equivalency education that, in a renewed way, would not fall back into past errors or turn this form of tuition excessively academic.

Key words: Educational Policy; Youth and Adult Education Policy; Brazil.

Referências bibliográficas

BEISIEGEL, Celso de Rui. Consideraçôes sobre a política da União para a educação de jovens e adultos analfabetos. Revista Brasileira de Educação, São Paulo, Jan./Abr. 1999, no 4, p. 26-34.

FÁVERO, Osmar, RUMMERT, Sônia Maria \& VARGAS, Sônia de. Formação de profissionais para a educação de jovens e adultos trabalhadores: A proposta da faculdade de educação da Universidade Federal Fluminense. In: Diversidade e desigualdade: Desafios para a educação na fronteira do século. 22a Reunião Anual da Anped, São Paulo, 1999. (Cd-Rom)

FLECHA GARCIA, Ramon. Efeito desnivelador y educación comunicativa: Educación de jovenes y personas adultas en España. Barcelona: Crea, 1996.

HADDAD, Sérgio. Tendências atuais na educação de jovens e adultos. Em Aberto, Brasília, out./dez. 1992, vol. 11, no 4, p. 3-12.

A educação de pessoas jovens e adultas e a nova LDB. In: BRZEZINSKI, Iria (Org.). LDB interpretada: Distintos olhares se entrecruzam. São Paulo: Cortez, 1997.

. \& DI PIERRO, Maria Clara. Satisfação das necessidades básicas de aprendizagem de jovens e adultos no Brasil: Contribuições para uma avaliação da década da Educação para Todos. São Paulo: Ação Educativa, 1999 (Paper). 
. DI PIERRO, Maria Clara \& FREITAS, Maria Virgínia. Perfil do atendimento em alfabetização de jovens e adultos no estado de São Paulo. Relatório de pesquisa. São Paulo: Cedi, 1993.

. \& SIQUEIRA, Maria Clara Di Pierro. Diagnóstico dos estudos e pesquisas sobre políticas, estrutura e funcionamento do ensino supletivo - função suplência. Relatório final de pesquisa. São Paulo: Cedi, 1988.

IBGE. Contagem da população: 1996. Brasília: IBGE, 1997.

JOIA, Orlando et al. Proposta curriculares de Suplência II ( $2^{\circ}$ segmento do ensino fundamental supletivo): Relatório de pesquisa. São Paulo: Ação Educativa, 1999.

MATO GROSSO. Secretaria de Educação. O ensino supletivo. Informe de pesquisa. Cuiabá: Seduc, 1998.

RECIFE. Secretaria Municipal de Educação. Perfil dos alunos de EBJA. Recife: SME, 1995.

RIBEIRO, Vera M. Masagão. Alfabetismo e atitudes: Pesquisa junto a jovens e adultos. São Paulo/Campinas: Ação Educativa/Papirus, 1998.

RIBEIRO, Vera M. Masagão et al. Educação de jovens e adultos: Proposta curricular para o $1^{\circ}$ segmento do ensino fundamental. São Paulo/ Brasília: Ação Educativa/MEC-SEF, 1997.

SÃO PAULO (Cidade). Secretaria de Educação. Perfil dos educandos de Suplência I, Suplência II e regular noturno da RME. São Paulo: SME, 1992.

TORRES, Rosa Maria. (1992). Educación para todos: La propuesta, la respuesta (1990-1999). Buenos Aires (apresentada no Painel Nueve años despues de Jomtien, Conferência Anual da Sociedade Internacional de Educação Comparada, Toronto, 14-18 de abril, 1999. 